\title{
Electrochemistry of single molecules and biomolecules, molecular scale nanostructures, and low-dimensional systems
}

\author{
Nazmutdinov, Renat R. ; Zinkicheva, Tamara T.; Zinkicheva, Tamara T.; Shermukhamedov , Shokirbek A. \\ ; Zhang, Jingdong; Ulstrup, Jens
}

\author{
Published in: \\ Current Opinion in Electrochemistry
}

Link to article, DOI:

10.1016/j.coelec.2017.11.013

Publication date:

2018

Document Version

Peer reviewed version

Link back to DTU Orbit

Citation (APA):

Nazmutdinov, R. R., Zinkicheva, T. T., Zinkicheva, T. T., Shermukhamedov, S. A., Zhang, J., \& Ulstrup, J. (2018). Electrochemistry of single molecules and biomolecules, molecular scale nanostructures, and lowdimensional systems. Current Opinion in Electrochemistry, 7, 179-187. https://doi.org/10.1016/j.coelec.2017.11.013

\section{General rights}

Copyright and moral rights for the publications made accessible in the public portal are retained by the authors and/or other copyright owners and it is a condition of accessing publications that users recognise and abide by the legal requirements associated with these rights.

- Users may download and print one copy of any publication from the public portal for the purpose of private study or research.

- You may not further distribute the material or use it for any profit-making activity or commercial gain

- You may freely distribute the URL identifying the publication in the public portal 


\section{Accepted Manuscript}

Electrochemistry of single molecules and biomolecules, molecular scale nanostructures, and low-dimensional systems

Renat R. Nazmutdinov, Tamara T. Zinkicheva ,

Shokirbek A. Shermukhamedov, Jingdong Zhang , Jens Ulstrup

PII:

$$
\text { S2451-9103(17)30180-1 }
$$

DOI:

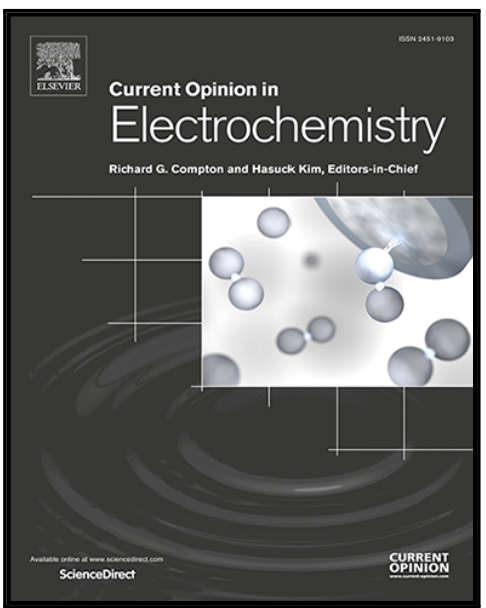

Reference:

To appear in: $\quad$ Current Opinion in Electrochemistry

Received date: $\quad 26$ October 2017

Revised date: $\quad 17$ November 2017

Accepted date: $\quad 17$ November 2017

Please cite this article as: Renat R. Nazmutdinov, Tamara T. Zinkicheva, Shokirbek A. Shermukhamedov, Jingdong Zhang, Jens Ulstrup, Electrochemistry of single molecules and biomolecules, molecular scale nanostructures, and low-dimensional systems , Current Opinion in Electrochemistry (2017), doi: 10.1016/j.coelec.2017.11.013

This is a PDF file of an unedited manuscript that has been accepted for publication. As a service to our customers we are providing this early version of the manuscript. The manuscript will undergo copyediting, typesetting, and review of the resulting proof before it is published in its final form. Please note that during the production process errors may be discovered which could affect the content, and all legal disclaimers that apply to the journal pertain. 


\section{Highlights}

- Single-molecule electrochemistry by STM in aqueous and ionic liquid media

- In situ STM and electrochemistry of single redox metalloprotein molecules

- Molecular scale nanoparticle catalysis of simple electrochemical electron transfer processes

- Molecular scale tubes as local confinement for molecular charge transfer processes

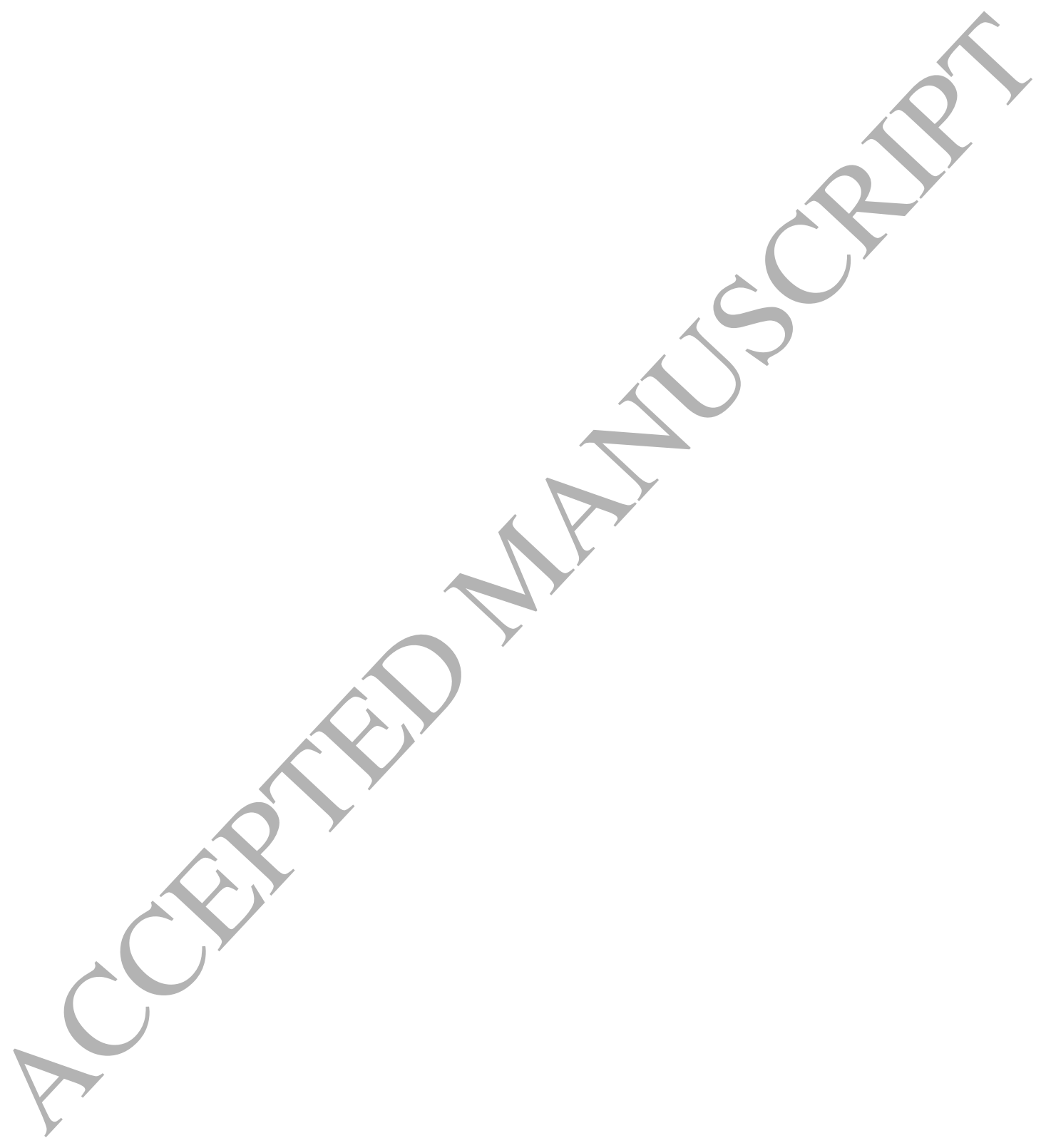




\title{
Electrochemistry of single molecules and biomolecules, molecular scale nanostructures, and low-dimensional systems
}

An integrated experimental, theoretical, and computational approach

\author{
Renat R. Nazmutdinov ${ }^{1 *}$, Tamara T. Zinkicheva ${ }^{l}$, Shokirbek A. Shermukhamedov ${ }^{1}$, \\ Jingdong Zhang ${ }^{2}$ and Jens Ulstrup ${ }^{2 *}$
}

${ }^{1}$ Kazan National Research Technological University, K. Marx Str., 68, 420015 Kazan, Republic of Tatarstan, Russian Federation

${ }^{2}$ Department of Chemistry, Building 207, Technical University of Denmark, 2800 Kongens

$$
\text { Lyngby, Denmark }
$$

\section{Highlights}

- Single-molecule electrochemistry by STM in aqueous and ionic liquid media

- In situ STM and electrochemistry of single redox metalloprotein molecules

- Molecular scale nanoparticle catalysis of simple electrochemical electron transfer processes

- Molecular scale tubes as local confinement for molecular charge transfer processes

Electrochemistry at ultra-small scales, where even the single molecule or biomolecule can be characterized and manipulated, is on the way to a consolidated status. At the same time molecular electrochemistry is expanding into other areas of sophisticated nano- and molecular scale systems including molecular scale metal and semiconductor nanoparticles (NPs) and other nanostructures, e.g. nanotubes, "nanoflowers" etc.. The new structures offer both new electronic properties and highly confined novel charge transfer environments.

\section{Introduction}

Chemical and biological sensing at ultra-small scales, and "molecular scale electronics" have been ultimate perspectives for single-molecule or single-entity (particles, tubes etc.) science $^{1,2}$. Molecular scale electrochemistry also discloses new properties or even phenomena different from macroscopic assemblies. The presence of two electrode surfaces in electrochemical in situ STM instead of a single electrode has for example disclosed new ET phenomena, possibly a rationale for often observed very high in situ STM current densities ${ }^{3-5}$. Molecular scale inorganic particles display single-ET charging in voltammetry ${ }^{6}$ and in situ tunneling spectroscopy (STS) ${ }^{7}$. Ionic liquid media are, further gaining importance, ${ }^{1,8,9}$ and "nanoimpacts" "hot" electrons and quantum dots", non-Gaussian solvent configurational fluctuations ${ }^{11}$, and electronic spill-over ${ }^{13,14}$ are still other electrochemical single-entity phenomena. New electrode materials and electrode configurations are finally prominent in developing nanoelectrochemistry, with $2 \mathrm{D}$ and $3 \mathrm{D}$ graphene and graphene/NP hybrid materials $^{15,16}$, core-shell $^{17,18}$ and Janus-like NPs ${ }^{19}$, 1D single carbon nanotubes ${ }^{20}$, and nanopørous electrodes ${ }^{21,22}$ as examples.

The present short review addresses three areas in prodigious single-entity electrochemistry, all in development, and reflecting the authors' views: (1) Single-(bio)molecule structure and reactivity. (2) Molecular scale inorganic NPs. (3) Low-dimensional inorganic nanoscale structures (tubes, bent and twisted graphene sheets) with specific electronic properties and also serving as confinement for ET and other reactivity. In addition to overviewing experimental and theoretical achievements, efforts in molecular dynamics (MD) and quantum chemical density functional (DFT) simulations are addressed. 


\section{Single-molecule and -biomolecule electrochemistry, and in situ STM}

Scanning tunneling and atomic force microscopy in aqueous electrolyte or ionic liquids under electrochemical control (in situ STM and AFM) has enabled approaching the ultimate limit of the single molecule in action, extending to single-molecule mapping of biomolecules such as metalloproteins and DNA-based molecules in natural environment ${ }^{23-30}$. Both non-covalent ${ }^{28}$ and much stronger chemisorptive molecular wiring to the electrode and the (in situ) STM or AFM tip are feasible ${ }^{27,29,30}$. Break-junction $(B-J)$, and $i(t)$ and $i(z)$ methods (i the current density, $\mathrm{t}$ the time and $\mathrm{z}$ the distance) are other notions ${ }^{31}$. In situ STM enables recording $t w o$ correlations, the (tunneling) current/bias $\mathrm{i}_{\text {tunn }} / \mathrm{V}_{\text {bias }}$ voltage correlation as in $\mathrm{UHV} / \mathrm{gas}$ environment, and the current/overpotential $i_{\text {tunn }} / \eta$ correlation (STS). The latter is reminiscent of electronic components with a gate electrode in addition to a source and a drain electrode.

\subsection{Some conceptual frames of single-molecule electrochemistry}

Following Tao's early work $(1996)^{32}$ a considerable number of organic redox molecules and transition metal complexes in aqueous and ionic liquid media have been mapped to singlemolecule resolution. ${ }^{1,23}$ A conceptual notion introduced early is the in situ STM/STS redox process as "hopping" with successive ET between tip and molecule, and between molecule and electrode ${ }^{3,33,34}$. The two-step feature is apparent in the current density form

$i\left(\eta ; V_{\text {bias }}\right)=e n \frac{k_{\text {tip }, \text { mol }} k_{\text {electr,mol }}}{k_{\text {mol }, \text { tip }}+k_{\text {electr }, \text { mol }}}$

$k_{\text {tip,mol }}, k_{\text {mol,tip }}$, and $k_{\text {electr,mol }}$ are the electrochemical rate constants, $e$ the electronic charge, and $n$ the number of electrons transferred in a single two-step STS event. In situ STS can be correlated with the electrochemical rate constants

$$
k\left(\eta ; V_{\text {bias }}\right)=\kappa_{e l} \frac{\omega_{e f f}}{2 \pi} \exp \left\{-\frac{\left[\lambda+e \eta\left(V_{\text {bias }} ; \xi ; \gamma\right]^{2}\right.}{4 \lambda k_{B} T}\right\}
$$

where $k$ represents the rate constants in eq.(1), $\lambda$ the reorganization free energy, $\kappa_{\mathrm{el}}$ the electronic transmission coefficient, $\omega_{\text {eff }}$ the effective vibrational frequency, $k_{\mathrm{B}}$ Boltzmann's constant, and $T$ the temperature. $\xi$ represents the electrode/molecule potential drop and $\gamma$ the bias voltage drop at the site of the molecule. A central outcome is a current maximum at

$$
\eta=\eta_{\max }=\frac{1}{\xi}\left(\frac{1}{2}-\gamma\right) V_{\text {bias }}
$$

$\eta_{\max }$ thus coincides with the equilibrium potential for symmetric tunneling junctions.

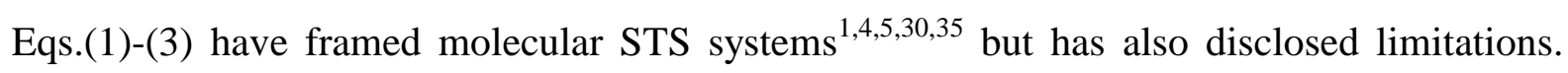
Transition metal complexes and metalloproteins for which comparison with electrochemical rate constants is feasible thus show significantly higher single-molecule conductivity than expected from the macroscopic rate constants ${ }^{4,5,23,27}$. Restricted solvent configurational fluctuations in the tunneling gap have been forwarded as one rationale ${ }^{7}$, which requires then attention to activationless ET. Coherent many-ET, $n>>1$ has also been suggested ${ }^{4,5,23}$. Other features in need of attention are: (a) The electrode materials; (b) ionic liquid media and high 
ionic strengths; (c) "quantum interference"35; and (d) the transition between superexchange and "hopping" as the overpotential and bias voltage are varied.

\subsection{Single-molecule in situ STM imaging and conductivity of redox metalloproteins}

"Long-range" ET (LRET) in biological charge transfer is long recognized ${ }^{36}$ LRET can refer to tunneling through the peptide frame between a metal centre and external reaction partners or electrode surfaces, with tunneling distances up to a couple of nanometers. LRET in larger protein complexes takes the form of multi-step "hopping"36 but shorter-range tunneling is still a feature of each "hop". In situ STM of horse heart cyt $c^{37}$ and horseradish peroxidase ${ }^{38}$ were the first single-molecule metalloprotein in situ STM targets. Following the introduction of the blue copper protein Pseudomonas aeruginosa azurin as a robust in situ STM target ${ }^{27,39}$, both much better resolved structural in situ STM and single-molecule in situ STS have been reported. Structural targets include the three major ET metalloprotein classes, the blue $\mathrm{Cu}-$ proteins $^{2,3,22,27-30}$, cytochromes $^{40,41}$, as well as a single $\mathrm{Fe}-\mathrm{S}$ protein representative, Pyrococcus furiosus ferredoxin ${ }^{42}$. In situ STM and AFM of multi-centre Achromobacter xylosoxidans $\mathrm{Cu}$-nitrite reductase (trimeric two-centre $\mathrm{Cu}$-enzyme) ${ }^{43}$ and several laccases is also reported ${ }^{44,45}$.

Here we cannot overview the multitude of electrochemical single-molecule metalloprotein systems, but focus on some issues relating to our discussion in Section 2.1. We note first that in addition to high-resolution structural mapping, single-molecule in situ STS is reported for at least two ET proteins, $P$. aeruginosa azurin ${ }^{28-30}$ and the four- $\alpha$ helix bundle $E$. coli cyt $b_{562}{ }^{4}$. Both display a strong in situ STS feature around the equilibrium potential (on-off ratios up to an order of magnitude), eq.(3). The data aceord with the multi-phonon two-step mechanism but prompt some observations. The azurin conductivity is quite close in the two cases of azurin binding to the $\mathrm{Au}(111)$-surface via the disulfide bond, viz $2.5^{29}$ and $3.3 \mathrm{nS}^{30}$, but notably lower, i.e. $0.4 \mathrm{nS}$ for azurin non-covalently attached via an octanethiol SAM, according with weaker azurin-electrode coupling through the $\mathrm{SAM}^{28}$. The latter data could be compared with electrochemical ET rate constants of $(0.5-1) \times 10^{3} \mathrm{~s}^{-1}$ (or higher). These would give about two orders of magnitude lower single-ET tunneling currents than observed. High currents are even more pronounced for cyt $b_{562}$ mutants with two oppositely located Cys residues inserted along either the long- or the short-axis. The conductivities vary only by a factor of two in spite of the distance difference and differently organized protein matter. The pattern accords with strongly adiabatic ET, $\kappa_{\mathrm{el}} \rightarrow 1$, but leaves open a need for invoking other features such as single-molecule ET coherence.

The second issue that we address is the intramolecular ET channels in multi-centre redox metalloproteins illustrated by two cases, A. xylosoxidans $\mathrm{CuNiR}^{43}$ and the two-heme protein Pseudomonas) stutzeri cyt $c_{4}$ (Fig.1 ${ }^{40,41}$. Focus is on the observation that binding of the protein to the electrode surface or binding of the enzyme substrate, here $\mathrm{NO}_{2}^{-}$triggers conformational changes in the protein framework, opening intramolecular ET channels.

Fig. 1

Cyt $c_{4}$ exchanges electrons in the ms-s time range with external reaction partners with no intramolecular ET between the two heme groups, Fig. ${ }^{40}$. On cyt $c_{4}$ binding to a SAMmodified $\mathrm{Au}(111)$-electrode surface, in vertical orientation as verified by in situ STM, Fig.1 and cyclic voltammetry, an efficient channel opens with intramolecular ET in the microsecond range. A theoretical analysis could suggest reasons for this behavior ${ }^{41}$. The reorganization free energy and driving force are little affected by the binding, but the 
transmission coefficient $\kappa_{\mathrm{el}}$ is exceedingly sensitive even to tiny structural changes. ET in the crystallographic structure is highly unfavorable, but small shifts of the heme planes, little costly in energy increase the transmission coefficient by orders of magnitude, Fig. $1^{41}$.

Similar considerations apply to $\mathrm{CuNiR}^{43}$. CuNiR, and many other enzymes mostly show no Faradaic electrochemistry, even though fast intramolecular ET $(5-50 \mathrm{~ms})$ between the Type I and Type II centres in solution has been detected ${ }^{46}$. On $\mathrm{NO}_{2}{ }^{-}$substrate binding fast interfacial electrocatalysis of $\mathrm{NO}_{2}{ }^{-}$reduction via the now opened intramolecular ET channel, however, appears. Electrochemical AFM could show that channel opening is accompanied by $1 \mathrm{~nm}$ structural enzyme "swelling" 43 . Features such as these have not been addressed before.

\section{Single-entity electrochemistry of inorganic nanoparticles}

Electrochemistry and electrocatalysis of metallic NPs has recently developed tremendously. We provide here a few observations for comparison with similar-size biomolecules and otherwise refer to recent reviews ${ }^{25,47,48}$. Molecular scale noble metal (and core-shell) NPs are long known as electrocatalysts in fuel cell and other processes. Here we address AuNP catalysis of simple ET reactions. Reactant, product, and reaction intermediates in, say fuel cell processes are adsorbed on the NPs, and it is expected that changes in the surface electronic structures can result in catalytic effects compared with planar electrode surfaces. PdNPs, PtNPs and AuNPs are, however, also catalysts of simple electrochemical ET processes. Horse heart cyt $c$ at $\mathrm{Au}(111)$-surfaces modified by functionalized alkanethiol SAMs is a representative system, Fig. $2^{49}$. The standard rate constant at an undecanoic acid $\mathrm{SAM}$ modified $\mathrm{Au}(111)$-surface is $4 \mathrm{~s}^{-1}$. Linking a thioctic acid (TA) modified $3 \mathrm{~nm}$ AuNP between cyt $c$ and the surface, the rate constant increases 20 -fold. "Normal" molecular matter would entirely block the ET process on such a distance increase.

Fig.2

Understanding such phenomena is an opening research area. Chazalviel and Allongue introduced a model of a SAM-bound AuNP monolayer" ${ }^{51}$, in which AuNPs form a "shortcircuiting" catalytic metallic layer on top of the SAM. This model has been used to frame observed weak distance dependent ET rate constants viaAuNPs adsorbed on functionalized alkanethiol modified polycrystalline Au-electrodes surfaces up to a SAM thickness of about 2 $\mathrm{nm}^{52}$. Another view is to focus on individual AuNPs and view the process as two-step, superexchange or hopping with consecutive ET between molecule and electrode via the AuNP ${ }^{13,49,53}$. Key in the two-step view is the NP size. Small particles $(\leq 2.5 \mathrm{~nm})$ display discrete single-ET charging reminiscent of molecules ${ }^{6,7}$, while the plasmonic electronic levels of larger NPs are continuous. In either superexchange or hopping efficient AuNP electronic overlap to either side is essential for facile LRET compared with planar metal surfaces. Sizeand metal-dependent electronic density "spillover" of the kind studied for simple alkali metals ${ }^{54}$ here be a core concept $t^{13,54}$. Other rationales for the AuNP catalyzed ET rate exhancement including deformation of the electrode surface SAM are discussed elsewhere ${ }^{55}$.

\section{Two new electrode materials for molecular scale electrochemistry}

\subsection{Nanotubes as confinement for transport and charge transfer processes}

"Nanotubes" represent extension from " $0-\mathrm{D}$ " NP to 1-D nanoscale structures. Nano- and picoampere cyclic and linear voltammetry of single-wall carbon nanotubes (SWCNT) has been reported $^{56-59}$, and experimental nanoscale electrochemistry findings now warrant molecular level theoretical analysis. General principles of such analysis are formulated ${ }^{60}$, and double layer effects specifically in the reduction of $\left[\mathrm{Fe}(\mathrm{CN})_{6}\right]^{3-14-}$ and $\mathrm{S}_{2} \mathrm{O}_{8}{ }^{2-}$ at conducting 
nanotubes modeled ${ }^{61,62}$ with intriguing expectations such as inverse Arrhenius behavior and disappearance of a "pit" in the current-voltage relations. Reactant - monoatomic metal (Ag, $\mathrm{Au}, \mathrm{Cu}, \mathrm{Pt})$ nanowire orbital overlap for the $\left[\mathrm{Fe}\left(\mathrm{OH}_{2}\right)_{6}\right]^{3+/ 2+}$ and $\left[\mathrm{Cr}\left(\mathrm{OH}_{2}\right)_{6}\right]^{3+/ 2+}$ couples in aqueous solution has further been addressed by quantum mechanical theory ${ }^{63}$. The electronic transmission coefficients were calculated and compared with $\mathrm{Me}(111) /$ water interfaces showing larger values for the nanowires at short distances, but significantly smaller values for larger distances. Lemay and associates ${ }^{64}$ reported the first current/voltage analysis using theory for ET across metallic and semiconducting SWCNTs and scanning tunneling spectroscopy.

Electrolyte structure and transport inside nanotubes are harder to address but in part understood. Chemical kinetics inside nanotubes is the next level of complexity but less understood. The structure of pure water inside SWCNTs was explored by X-ray diffraction and NMR techniques ${ }^{65,66}$ and by Molecular Dynamics (MD) ${ }^{67}$ simulations successfully employed to hydrated ions ${ }^{68,69}$ and hydrated proton transport in the nanotubes ${ }^{70-72}$, Fig.3. Nuclear quantum effects was incorporated using $a b$ initio $\mathrm{MD}^{71,72}$ and path integral techniques ${ }^{71}$. CNT mobility of water molecules and hydrated protons is higher than in bulk solution, attributed to the ordered hydrogen bonds between water molecules in the CNT channels and weak interaction between water and the CNT walls. The first cationic coordination shells were found to be considerably less ordered in the nanotube than in bulk solution, but with only minor anion first coordination shell changes.

Fig.3

Understanding chemical reactions in confined nanotube space is highly challenging with potential applications, reviewed recently ${ }^{73}$ with intriguing examples of electrochemical reactions. CNTs filled by electrolyte are also transport and charge transfer models for nanosize pores. Primary attention is given to catalytic effects with CNTs shown to modify the electronic catalyst properties. ${ }^{74}$. Ion transport through single electrolyte filled CNTs was further probed using microfluidic devices on a silicon wafer ${ }^{74-77}$. Cations are preferentially transported, for example with fívefold ion diffusion enhancement in a $1.6 \mathrm{~nm}$ SWNT72 as compared with the other carbon nanotubes, scaling as $\mathrm{Li}^{+}>\mathrm{K}^{+}>\mathrm{Cs}^{+}>\mathrm{Na}^{+76}$. Similar effects were found for a vertically aligned MWCNT membrane ${ }^{78}$. This might be understood taking into account the interplay between different factors: (1) specific water structure in a confined space where association of $\mathrm{H}_{2} \mathrm{O}$ molecules plays an important role; (2) reduced hydration sheath of ions, (3) the size difference between cations and anions; and (4) coupling of ions to the hydrodynamic modes of water associates. Simulations at the molecular level are needed to gain a deeper insight into such challenging experimental observations. ${ }^{76}$.

Classical MD simulations of the kinetics of simple redox couples in nanopores have, finally been reported $\mathrm{d}^{79,80}$ and framed by molecular ET theory. These computational results are, however, mutually contradictive. ET rate enhancement in nano-confined space ${ }^{80}$, but a rate decrease compared with bulk solution ${ }^{79}$, both based on MD has thus been concluded.

\subsection{A note on graphene electrode materials}

Even perfect graphene is attractive for electrochemistry of simple redox couples due to unique electronic properties (the Dirac point, nearly linear ascending and descending DOS near the Fermi level). Investigating such an electronic structure in current-voltage relations of adiabatic and diabatic ET processes is tempting and challenging. An experimental challenge is to fix and charge a graphene sheet. For example, if graphene resides on another electrode ${ }^{81}$, 
does the latter then affect the graphene electronic structure? Graphene holds other promise as 2D-electrode materials, with catalytic properties attributed in the first place to defects, the role of which in ET processes is, however, poorly understood.

The kinetics of redox processes at the graphene edge (linear topological defect) is so far the most studied ${ }^{82,83}$. The graphene edge activity can be understood from scanning electron spectroscopy, which discloses local electronic states below the Fermi level at zigzag-type ${ }^{84}$, but not at chair-type graphene edges. Graphene sheet vacancies also results in local electronic states which makes the vacancies catalytically active ${ }^{85}$. The rate constant of the $\mathrm{FcMeOH} / \mathrm{FcMeOH}^{+}$redox process was thus found to increase by two orders of magnitude on increasing the vacancy concentration to $5 \times 10^{12} \mathrm{~cm}^{-2}$ (i.e. $\approx 2 \mathrm{~nm}$ between the defects) ${ }^{85}$. Oxidation of the graphene surface by dioxygen can be catalytically enhanced by nitrogen doping or by oxygen surface functionalities ${ }^{86,87}$. For further discussion of the prodigious experimental, theoretical, and computational approaches relating to pure and applied properties of graphene and graphene composite materials, we refer to Refs.15 and 16 as representatives of a voluminous literature.

\section{Some perspectives}

Electrochemistry of single molecular scale entities covers highly diverse targets, developed as new research over the last decade. Entities include single small molecules such as alkanethiols, and large biological molecules such as metalloproteins and DNA based molecules. Interfacial electrochemical single-entity ET also covers a prodigious range of inorganic particle, wire, rod, "flower", layer etc. structures all the way from "0D" via 1D and $2 \mathrm{D}$, to $3 \mathrm{D}$ structures, structurally and functionally understood to different degrees. We have focused on interplay between advanced experimental studies, quantum mechanical charge transfer theory, and quantum and computational chemistry, and selected for discussion of three single-entity system classes. Electrochemistry of single molecules seems best understood, much due to increasing use of the scanning probe microscopies, in situ STM and AFM. Structural and functional mapping have reached high resolution, but we have also noted unresolved challenges, such as conformational changes on electrochemical adsorption of large biomolecules, and often very high tunneling current densities (per molecule).

Functional Au-, Pt- and core-shell NPs are used biomedically, in catalysis, electrochemical sensing, and in fuel cells. Controlled NP synthesis is established, but high-resolution structural properties, say of thiol-protected AuNPs, and understanding of the Au-S bond ${ }^{88}$ is only now offering firmer basis and rational routes towards AuNPs in real use. Fundamentals of metallic NPs are far from understood, but the electrochemistry of composite nanowires, nanorods, nanoflowers, and single CNTs, offer even greater challenges. Mere atomic intercalation changes drastically the electronic CNT structure and reactivity. Electrochemistry of single nanowires, nanorods, and nanoflowers, and experimental and computational probing of electrochemical reactivity inside nanotubes is thus only just beginning,

With single-entity electrochemistry moving, entirely new systems of interest for electrochemical and in situ STM/AFM single-entity probing may appear. One new area could be electrical, optoelectronic, and magnetic properties of layered perovskites ${ }^{89}$. Surfaces of these 2D materials could be locally, using spintronics notions and magnetic STM/AFM tips. A second area is molecular magnets. These are engineered building blocks of strongly magnetic transition metal or rare earth complexes, which can be hierarchically fine-tuned into magnetic materials ${ }^{90}$. Local electrochemical STM/AFM probing of molecular magnets would support exciting new materials science, and more specifically address often overlooked spin 
effects in elementary ET processes. The developments in NP applications demonstrate what can be achieved by interdisciplinary research that includes quantum chemical calculations, experimentation and modern microfabrication ${ }^{14}$. Progress in the new areas will equally depend on such interplay.

\section{Acknowledgement}

Financial support from The Danish Council for Independent Research for YDUN project (DFF 4093 00297), the Lundbeck Foundation (R141-2013-13273), and the Russian Science Foundation (17-1301274) is acknowledged.

(1). Nichols, R. J.; Higgins, S. J.: Single Molecule Nanoelectrochemistry in Electrical Junctions. Acc. Chem. Res. 2016, 49, 2640-2648.

- Detailed and updated overview of electrochemistry and in situ scanning tunnelling microscopy of redox molecules at the single-molecule level

(2). Single-entity Electrochemistry, Faraday Discussions 2016, 193, 1-551.

(3). Kuznetsov, A. M.; Ulstrup, J.: Mechanisms of in Situ Scanning Tunnelling Microscopy of Organized Redox Molecular Assemblies. J. Phys.Chem. A 2000, 104, 11531-11540. Errata: 2001, 105, 7494-7494.

(4).Della Pia, E. A.; Chi, Q.; Macdonald, J. E.; Ulstrup, J,; Jones, D. D.; Elliott, M.: Fast electron transfer through a single molecule natively structured redox protein. Nanoscale 2012, 4, 71067113.

(5). Albrecht, T.; Guckian, A.; Kuznetsov, A.M.; Vos, J.G.; Ulstrup, J.: Mechanism of Electrochemical Charge Transport in Individual Transition Metal Complexes. J. Am. Chem. Soc. 2006, 128, 1732-1738.

(6). Chen, S.W., Murray, R.W.; Feldberg,S.F.: Quantized Capacitance Charging of Monolayerprotected Gold Clusters. J. Phys. Chem. B 1998, 102, 9898-9907.

(7). Albrecht, T.; Mertens, S.F.L.; Ulstrup, J,: Intrinsic Multi-state Switching of Gold Clusters through Electrochemical Gating, J. Am. Chem. Soc. 2007, 129, 9162-9167.

(8). Albrecht, T.; Moth-Poulsen, K.; Christensen, J. B.; Hjelm, J.; Bjornholm, T.; Ulstrup, J.: Scanning tunneling spectroscopy in an ionic liquid. J. Am. Chem. Soc. 2006, $128,6574-$ 6575.

(9). Yan, J._W.; Tian,_Z.-Q.; Mao, B.: Molecular-level Understanding of Electric Double Layer in Ionic Liquids. Curr. Opin. Physical and Nanoelectrochemistry 2017. In press.

(10). Bartlett T.R.; Sokolov, S.V.; Compton, R.G.: Nanoparticle Photochemistry via Nano-I Impacts, Russian J. Electrochemistry 2016, 52, 1131-1136.

(11). Diesing, D.; H.; Otto, A.: Surface Reactions with Hot Electrons and Hot Holes in Metals. Surf. Sci. 1995, 331, 289-293.

(12). Waskasi, M.M.; Newton, M.D.; Matyushov.D.V.: Impact of Temperature and Non-Gaussisn Statistics on Electron Transfer in Donor-Bridge-Acceptor Molecules. J.Phys. Chem. B. 2017, 121, 2665, 2676.

(13). F. Liu, K. Khan, J.-H. Liang, J.-W. Yan, D.-Y. Wu, B.-W. Mao, P.S. Jensen, J. Zhang, J. Ulstrup: On the Hopping Efficiency of Nanoparticles in the Electron Transfer across Self-Assembled Monolayers, ChemPhysChem 2016, 14, 952-957.

-• Demonstration that the kinetics of electron transfer across a metal|insulator|metal particle|redox couple system can be treated as a two-step ET reaction including electronic spill-over.

(14). Schiffrin, D.J.: Current Topics in Physical and Nanoelectrochemistry, Curr. Opin. In Physical and Nanoelectrochemistry 2017, in press. 
- Important recent review of selected electrochemical aspects on metallic nanoparticles.

(15). Geim, A.K.; Novoselov, K. S.: The Rise of Graphene, Nature Materials, 2007, 6, 183-191.

(16). Park, S.; Ruoff, R.S.: Chemical Methods for the Production of Graphene', Nature Nanotechnology, 2009, 4, 217-224.

(17). Engelbrekt, C.; Šešelj, N.; Poreddy, R.; Riisager, A.; Ulstrup, J.; Zhang, J.: Atomically Thin Pt Shells on Au Nanoparticle Cores: Facile Synthesis and Efficient Synergetic Catalysis. J. Mater. Chem. A, 2016, 4, $3278-3286$.

(18). S Šešelj, N.; Engelbrekt, C.; Ding, Y.; Hjuler, H. A.; Ulstrup, J.; Zhang, J.: Tailored Electron Transfer Pathways in Aucore/Ptshell-graphene Nanocatalysts for Fuel Cells, Advanced Energy Materials, accepted October 2017.

(19). Walther, A.; Müller. A.H.E.: Janus Particles: Synthesis, Self-Assembly, Physical Properties and Applications. Chem. Rev. 2013, 113, 5194-5261.

(20. Dudin, P.V.; Snowden, M.E.; Macpherson, J.V.; Unwin, P.R.:. Electrochemistry at Nanoscale: Individual Single-Walled Carbon Nanotubes (SWCNTs) and SWCNT-Templated Metal Nanowires. ACS Nano, 2011, 5, 10017-10025.

(21). Merlet, C.; Rotenberg, B.; Madden, P.A.; Taberna, P.-L.; Simon, P.; Gogotsi, Y.; Salanne, M.: On the Molecular Origin of Supercapacitance in Nanoporous Carbon Electrodes. Nature Materials. 2012, 11, 306-310.

(22). Ding, Y.; Zhang, Z.: Nanoporous Metals for Advanced Energy Technologies 2016, Springer International Publishing AG, Switzerland.

(23) Zhang, J.; Kuznetsov, A. M.; Medvedev, I. G.; Chi, Q.; Albrecht, T.; Jensen, P. S.; Ulstrup, J.: Single-Molecule Electron Transfer in Electrochemical Environments. Chem. Rev. 2008, 108, 2737-2791.

- Detailed overview of electrochemical electron transfer and in situ scanning tunnelling microscopy imaging of single molecules and biomolecules.

(24). Salvatore, P.; Zeng, D.; Karlsen, K. K.; Chi, Q.; Wengel, J.; Ulstrup, J.: Electrochemistry of Single Metalloprotein and DNA-Based Molecules at $\mathrm{Au}(111)$ Electrode Surfaces. Chemphyschem 2013, 14, 2101-2111.

(25). Wang, Y.; Shan, X.; Tao, N.: Emerging Tools for Studying Single Entity Electrochemistry, Faraday Discussions on Single-entity Electrochemistry. 2016, 193, 939.

(26). Singh, P.S.; Lemay, S. G.: Stochastic Processes in Electrochemistry. Anal. Chem. 2016, $88,5017-5027$.

(27). Q. Chi, Q.; Zhang, J.; Nielsen, J.U.; Friis, E.P.; Chorkendorff, I.; Canters, G.W.; Andersen, J.E.T.; Ulstrup, J.: Molecular Monolayers and Interfacial Electron Transfer of Pseudomonas Aeruginosa Azurin on Au(111)., J. Am. Chem. Soc. 2000, 122 4047-4055.

- First detailed single-molecule study of the blue copper protein azurin, followed and picked up by other groups.

(28). Chi, Q.; Farver, O.; Ulstrup, J.: Long-range Protein Electron Transfer Observed at the Single-molecule Level: In Situ Mapping of Redox-gated Tunneling Resonance. Proc. Nat. Acad. Sci. USA 2005, 102, 16203-16208.

(29). Alessandrini, A.; Gerunda, M.; Canters, G. W.; Verbeet, M. P.; Facci, P.: Electron tunnelling through azurin is mediated by the active site $\mathrm{Cu}$ ion. Chem. Phys. Lett. 2003, 376, 625-630.

(30). Lopez-Martinez, M.; Artés, J.M.; Sarasso, V.; Carminati, M ; Diez-Perez, I; Sanz, F F. ; Gorostiza,: P. Differential Electrochemical Conductance Imaging at the Nanoscale, Small 2017, 13, Art. No. UNSP 1700958.

(31). Haiss, W.; Nichols, R.J.; van Zalinge, H.; Higgins, S.J.; Bethell, D.; Schiffrin, D.J.: Redox State Dependence of Single Molecule Conductivity, J. Am. Chem. Soc. 2003, 125 , 
15294-15295.

(32). Tao, N. J.: Probing Potential-Tuned Resonant Tunneling through Redox Molecules with Scanning Tunneling Microscopy. Phys. Rev. Lett. 1996, 76, 4066-4069.

- • First report of electrochemical single-molecule tunnelling/overpotential spectroscopy.

(33). Kuznetsov, A.M.; Ulstrup, J.: Dissipative Relaxation through a Low-energy Intermediate Electronic State in 3-Level Electron Transfer. Chem. Phys. 1991, 157, 25-33.

(34). Kuznetsov, A.M.; Ulstrup, J.; Sommer-larsen, P.: Resonance and Environmental Fluctuation Effects in STM Currents through Large Adsorbed Molecules. Surf. Sci. 1992, 275, 52-64.

(35). Bock, S.; Al-Owaedi, O.A.; Eaves, S.G.; Milan, D.C.; Lemmer, M.; Skelton, B.W.; Osorio, H.M.; Nichols, R.J.; Higgins, S.J.; Cea, P.; Long, N.J.; Albrecht, T.; Martin, S.; Lambert, C.J.; Low, P.J.: Single-Molecule Conductance Studies of Organometallic Complexes Bearing 3-Thienyl Contacting Groups. Chemistry A European Journal 2017, 23, 2133-2143.

(36). Winkler, J.R.; Gray, H.B.: Electron Flow through Metalloproteins. Chem. Rev. 2014. 114, 33693380 .

\section{- Detailed updated review of electron transport through metalloproteins}

(37). Andersen, J.E.T.; Møller, P.; Pedersen, M.V.; Ulstrup, J.: Cytochrome-c Dynamics at Gold and Glassy Carbon Surfaces Monitored by In-situ Scanning Tunnel Microscopy. Surf. Sci. 1995, 325, 193-205.

(38). Zhang, J.; Chi, Q.; Dong, S.J.; Wang, E.: In situ Electrochemical Scanning Tunnelling Microscopy Investigation of Structure for Horseradish Peroxidase and its Electrocatalytic Property. Bioeletrochem. Bioenerg. 1996, 39, 267-274.

(39). Friis, E.P.; Andersen, J.E.T.; Madsen, L.L.; Møller, P.; Ulstrup, J.: In Situ STM and AFM of the Copper Protein Peudomonas Aeruginosa Azurin, J. Electroanal. Chem. 1997, 431, 35- 38.

(40). Chi, Q.; Zhang, J.; Arslan, T.; Borg, L.; Petersen, G.W.; Christensen, H.E.M.; Nazmutdinov, R.R.; Ulstrup, J.: Approach to Interfacial and Intramolecular Electron Transfer of the Diheme Protein Cytochrome $c_{4}$ Assembled on Au(111)-Surfaces. J. Phys. Chem. B 2010, 114, 5617-5624.

(41). Nazmutdinov, R.R.; Bronshtein, M.D.; Zinkicheva, T.T.; Chi, Q.; Zhang, J.; Ulstrup, J.: Modeling and Computations of the Intramolecular Electron Transfer in the TwoHeme Protein Cytochrome c4. Phys. Chem. Chem. Phys. 2012, 14 5953-5965.

(42). Zhang, J.; Christensen, H.E.M.; Ooi, B.L.; Ulstrup, J: In Situ STM and Direct Electrochemistry of Pyrococcus Furiosus Ferredoxin Assembled on Thiolate-modified Au(111) Surfaces. Langmuir 2004, 20, 10200-10207.

(43). Hao, X.; Žhang, J.; Christensen, H.E.M.; Wang, H.; Ulstrup, J.: Electrochemical Single-molecule AFM of the Redox Metalloenzyme Copper Nitrite Reductase in Action, ChemPhysChem 2012, 13, 2919-2924

(44). Climent, V.; Zhang, J.; Friis,E.P.; Østergaard, L.H.; Ulstrup, J.: Voltammetry and In Situ Scanning Tunneling Microscopy of Laccases and Bilirubin Oxidase in Electrocatalytic Dioxygen Reduction on Au(111) Single-crystal Electrodes. J. Phys. Chem. C 2012, 116, 1232-1243.

(45). Traunsteiner, C.; Sek, S.; Huber, V.; Valeron-Vidal, C.; Kunze-Liebhäuser, J.: Laccase Immobilized on a Mixed Monolayer on $\mathrm{Au}(111)$ - Structure Dependent Activity towards Oxygen Reduction. Electrochim. Acta 2016, 213, 761-770.

(46). Suzuki, S.; Kataoka, K.; Yamaguchi, K.: Metal Coordination and mechanism of Multicopper Nitrite Reductase, Acc. Chem. Res. 2000, 33, 728-735.

(47). Kleijn, S.E.F.; Lai, S.C.S.; Koper, M.T.M.; Unwin, P.R.: Electrochemistry of Nanoparticles. Angew. Chem. Int. Ed. 2014, 53, 3558-3586.

- Recent detailed overview of nanoparticle electrochemistry.

(48). Oja, S.M.; Fan, Y.; Armstrong, C.M.; Defnet, P.; Zhang, B.: Nanoscale 
Electrochemistry Revisited, Anal. Chem. 2016, 88, 414-430.

(49). Jensen, P.S.; Chi, Q.; F.B. Grumsen, Abad, J.M.; Horsewell, A.; Schiffrin. D.J.; Ulstrup, J. Gold Nanoparticle Assisted Assembly of a Heme Protein for Enhancement of Long-range Interfacial Electron Transfer, J. Phys. Chem. C 2007, 111, 6124-6132.

(50). Li, X.; Lin, C. Batchelor-McAuley, C.; Laborda, E.; Shao, L.; Compton, R.G.: New Insights into Fundamental Electron Transfer from Single Nanoparticle Voltammetry. $J$. Phys. Chem. Lett. 2016, 7, 1554-1558.

(51). Chazalviel, J.-N. Allongue, P.: On the Origin of the Efficient Nanoparticle Mediated Electron Transfer across a Self-Assembled Monolayer, J. Am. Chem. Soc. 2011, 133, 762764.

- This paper presents a two-step model for electron transfer processes via an array of metal nanoparticles.

(52). Barfidokht, A.; Ciampi, S.; Luais, E.; Darwish, N.; Gooding, J.J.: Distance-Dependent Electron Transfer at Passivated Electrodes Decorated by Gold Nanoparticles. Anal. Chem. 2013, 85, 1073-1080.

(53). Jensen, P.S.; Chi,Q.; Zhang, J.; Ulstrup, J.: Long-range Electrochemical Electron Transfer of Pseudomonas Aeruginosa Azurin-gold Nanoparticle Hybrid Systems. J. Phys. Chem. C 2009, 113, 13993-14000.

(54). Kresin, V.V.: Collective Resonances and Response Properties of Electrons in Metal Clusters. Phys. Rept. 1992, 220, 1-52.

(55). Kissling, G.; Miles, D.O.; Fermin, D.J.: Electrochemical Charge Transfer Mediated by Metal Nanoparticles and Quantum Dots. Phys. Chem. Chem. Phys. 2011, 13, 2117521185.

(56). P.R. Unwin, P.R.; Güell, A.G.; Zhang, G.: Nanoscale Electrochemistry of $\mathrm{sp}^{2}$-Carbon Materials: From Graphite and Graphene to Carbon Nanotubes. Acc. Chem. Res. 2016, 49, 2041-2048.

- - Important and comprehensive recent review of redox processes at carbon nanotubes.

(57). Hodson, H.; Li, X.; Batchelor-McAuley, C.; Shao, L.; Compton, R: Single Nanotube Voltammetry: Current Fluctuations are Due to Physical Motion of the Nanotube. J. Phys. Chem. 2016, 120, 6281-6286.

(58). Zheng, M.; Diner, B.A.: Solution Redox Chemistry of Nanotubes. J. Am. Chem. Soc. 2004, 126, 15490-15494.

(59). Larromore, L.; Nád, S. Zhou, X.; Abruna, H.; McEuen, P.L.: Probing Electrostatic Potentials in Solution with Carbon Nanotube Transistors. Nano Lett. 2006, 6, 1329-1333.

(60). Chen, S.; Liu, Yu.: Heterogeneous Electron Transfer at Nanoscopic Electrodes: Importance of Electronic Structures and Electric Double Layers. Chem. Soc. Rev. 2014, $43,5372-5386$.

(61). Nazmutdinov, R.R.; Bronshtein, M.D.; Schmickler, W.: Electron Transfer across a Conducting Nanowire (-Tube)/Electrolyte Solution Interface. Electrochim. Acta. 2009, $55,68-77$.

(62). Nazmutdinov, R.R.; Bronshtein, M.D.; Berezin, A.S.; Soldano, G.; Schmickler, W.: Bond Breaking Electron Transfer across a Conducting Nanowire (Nanotube)/Electrolyte Solution Interface: the Role of Electrical Double Layer Effects. J. Electroanal. Chem. 2011, 660, 309-313.

(63). Nazmutdinov, R.R.; Berezin, A.S.; Soldano, G.; Schmickler, W.: Orbital Overlap Effects in Electron Transfer Reactions across a Metal Nanowire/Electrolyte Solution Interface. J. Phys. Chem. C 2013, 117, 13021-13027.

- First quantum mechanical study of ET processes at metallic nanowires vs. Met(111) surfaces 
(64.Heller, I.; Kong, J.; Williams, K.A.; Dekker, C.; Lemay, S.: Electrochemistry of SingleWalled Carbon Nanotubes: The Role of Band Structure and Quantum Capacitance. $J$. Am. Chem. Soc. 2006, 128, 7353-7359.

(65). Paineau E., Albouy P.A., Rouzire S., Orecchini A., Rols S,, Launois P.: X-ray Scattering Determination of the Structure of Water during Carbon Nanotube Filling. Nano Lett. 2013, 13, 1751-1756.

(66). Liu X., Pan X., Zhang S., Han X., Bao X.: Diffusion of Water inside Carbon Nanotubes Studied by Pulsed Field Gradient NMR Spectroscopy. Langmuir 2014, 30, 8036-8045.

(67). Alexidis A., Kassinas, S.: Molecular Simulation of Water in Carbon Nanotubes. Chem. Rev. 2008, 108, 5014-5034.

(68). Shao Q., Huang L., Zhou J., Lu L., Zhang L., Lu X., Jiang S., Gubbins K.E., Shen, W.: Molecular Simulation Study of Temperature Effect on Ionic Hydration in Carbon Nanotubes. Phys. Chem. Chem. Phys. 2008, 10, 1896-1906.

(69). Shao Q., Zhou J., Lu L., Lu X., Zhu Y., Jiang S.: Anomalous Hydration Shell Order of $\mathrm{Na}^{+}$and $\mathrm{K}^{+}$inside Carbon Nanotubes. Nano Lett. 2009, 9, 989-994.

(70). Cao Z., Peng Y., Yan N., Li S., Li A., Voth G.A.: Mechanism of Fast ProtonTransport along One-dimensional Water Chains Confined in Carbon Nanotubes. J. Am. Chem. Soc. 2010, 132, 11395-11407.

(71). Chen J., Li X.Z., Zhang Q., Michaelides A., Wang E.: Nature of Proton Transport in a Water-filled Carbon Nanotube and in Liquid water. Phys. Chem. Chem. Phys. 2013, 15, 6344-6349.

- Mechanism of proton transport in a nanotube investigated by Molecular Dynamics simulations incoporating quantum mechanical tunneling effects.

(72). Mann D.J., Halls M.D.: Water Alignment and Proton Conduction inside Carbon Nanotubes. Phys. Rev. Lett. 2003, 90, 195503-195506.

(73). Miners, S.A., G.A. Rance, A.N. Khlobystov: Chemical Reactions Confined within Carbon Nanotubes. Chemical Society Reviews, 2016, 45, 4727-4746.

(74). Lee, C.Y.; Choi, W.; Han, J.H.; Strano, M.S:. Coherence Resonance in a Single-Walle Carbon Nanotube Ion Channel. Science, 2010, 329, 1320-1324.

(75). Pang, P., He, J ; Park, J.H.; Krstic, PS ; Lindsay, S.: Origin of Giant Ionic Currents in Carbon Nanotube Channels. ACS Nano, 2011, 5, 7277-7283.

(76). Choi, W,; Ulissi, Z.W.; Shimizu, S.F.E.; Bellisario, D.O.; Ellison, M.D.; Strano, M.S.: Diameter-dependent Ion Transport through the Interior of Isolated Single-walled Carbon Nanotubes. Nature Communications, 2013, 4, Art. No. 2397, 8 pp.

(77). Amiri, H.; Shepard, K.L.; Nuckolls, C.; Sanchez, R.H.: Single-Walled Carbon Nanotubes: Mimics of Biological Ion Channels. Nano Letters, 2017, 17, 1204-1211.

(78). Pilgrim, G.A., Leadbetter, J.W.; Qiu, F.; Siitonen, A.J.; Pilgrim, S.M.; Krauss, T.D.: Electron Conductive and Proton Permeable Vertically Aligned Carbon Nanotube Membranes. Nano Letters. 2014, 14, 1728-1733.

(79). Li Z.J., Jeanmairet G., Méndez-Morales T., Burbano M., Haefele M., Salanne M.: Confinement Effects on an Electron Transfer Reaction in Nanoporous Carbon Electrodes. J. Phys. Chem. Lett.. 2017. 8, 1925-1931.

(80). Remsing R.C., McKendry L.G., Srogin D.R., Klein M.L., Zdila M.J. Frustrated Solvation Structures Can Enhance Electron Transfer Rates. J. Phys. Chem. Lett. 2015, 6, 4804-4808.

(81). Wang H., Shan X., Chen H.-Y., Tao N. Pauli Repulsion-Induced Expansion and 
Electrochemical Properties of Graphene. Nano Lett. 2017, 17, 236-247.

- - Effect of surface charge on the expansion of a graphene electrode experimentally explored for the first time.

(82). Yuan, W., Zhou, Y., Li, Y., Li, C., Peng, H., Zhang, J., Liu, Z., Dai, L., and Shi, G.: The Edge- and Basal-plane-specific Electrochemistry of a Single-layer Graphene Sheet. Sci. Rept. 2013, 3, Art. No. 2248, 7 pp.

(83). Banerjee, S.; Shim, J.; Rivera, J.; Jin, X.; Estrada, D.; Solovyeva, V.; You, X.; Pak, J.; Pop, E.; Aluru, N.; Bashir, R.: Electrochemistry at the Edge of a Single Graphene Layer in a Nanopore. ACS Nano. 2013, 7, 834-843.

(84). Niimi, Y., Matsui, T., Kambara, H., Tagami, K., Tsukada, M., and Fukuyama, H.: Scanning Tunneling Microscopy and Spectroscopy of the Electronic Local Density of States of Graphite Surfaces near Monoatomic Step Edges. Physical Review B, 2006, 73, Art. No. 085421.

(85). Zhong, J.-H., Zhang, J., Jin, X., Liu, J.-Y., Li, Q., Li, M.-H., Cai, W., Wu, D.-Y., Zhan, D., and Ren, B.: Quantitative Correlation between Defect Density and Heterogeneous Electron Transfer Rate of Single Layer Graphene.) J. Am. Chem. Soc. 2014, 136, 16609-16617.

(86). Li, Y., Wang, J., Li, X., Geng, D., Banis, M.N., Li, R., and Sun, X.: Nitrogen-doped Graphene Nanosheets as Cathode Materials with Excellent Electrocatalytic Activity for High Capacity Lithium-oxygen Batteries. Electrochem. Comm. 2012, 18, 12-15

(87). Wang, S., Dong, S., Wang, J., Zhang, L., Han, P., Zhang, C., Wang, X., Zhang, K., Lan, Z., and Cui, G.: Oxygen-enriched Carbon Material for Catalyzing Oxygen Reduction towards Hybrid Electrolyte Li-air Battery. Journal of Materials Chemistry 2012, 22, 21051-21056.

(88). $\quad$ Reimers, J.R.; Ford, M.J.; Marcuccio, S.; Ulstrup, J.; Hush, N.S.: Competition of van der Waals and Chemical Forces on Gold-sulfur Surfaces and Nanoparticles. Nature Rev. Chem. 2017, 1, Art. No. 0017, 11 pp.

- . Detailed discussion of the fundamental nature of the Au-S bond in thiol bonding to AuNPs and planar Au-surfaces.

(89). Manser, J.S.; Christians, J.A.; Kamat, P.V.: Intriguing Optoelectronic Properties of Metal Halide Perovskites. Chem. Rev. 2016, 116, 12956-13008.

(90). Pedersen, K.S.; Bendix, J.; Clerac, R.: Single-molecule Magnet Engineering: Building-block Approaches. Chem. Comm. 2014, 50, 4396-4415.

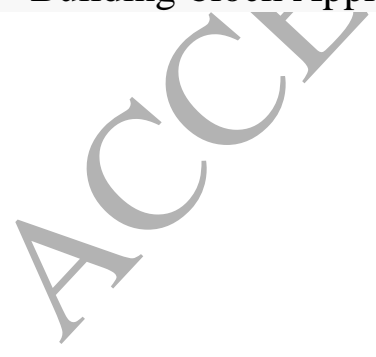



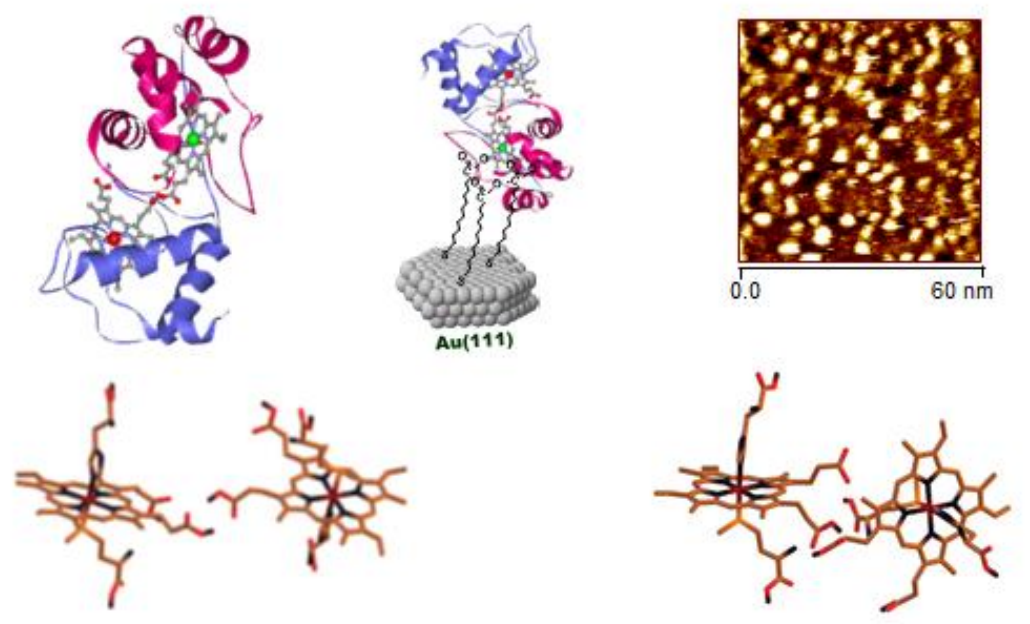

\section{Fig. 1}

Pseudomonas stutzeri cyt $c_{4}$ (PDP code 1EPT). Top left: Crystal structure to show the highpotential C- (red, positively charged) and low-potential $\mathrm{N}$-domain (blue, negatively charged) and the equilibrium orientation of the two heme groups. These are bound by a strong H-bond, but orientation and distance are unfavourable for fast intramolecular ET. Top middle: Cyt $c_{4}$ immobilized via the $\mathrm{C}$-domain on a $\mathrm{Au}(111)$-electrode surface modified by a (negatively charged) $\omega$-decanoic SAM. Top right: In situ STM image showing that vertical cyt $c_{4}$ orientation on the SAM modified surface prevails. Bottom left and right: Two cyt $c_{4}$ structures to illustrate conformational fluctuations needed for facile intramolecular ET. To the left is the equilibrium structure. To the right the hydrogen bond between the heme groups is broken (at low energy cost) and the heme planes brought closer towards better electronic overlap, strongly facilitating intramolecular ET. Adapted from Refs.40 and 41. 

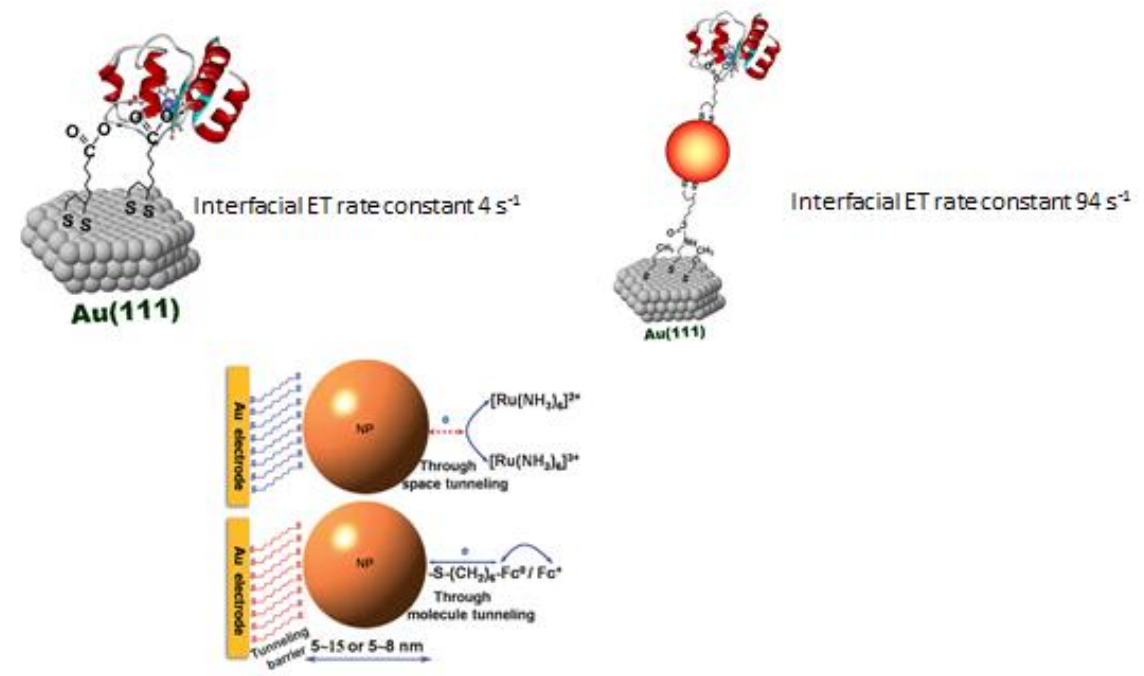

Fig. 2

Illustration of AuNP catalysis of interfacial electrochemical ET. Top left: Horse heart cyt $c$ electrostatically attached to a 11-mercaptoundecanoic acid SAM (negatively charged,) via the positively charged surface domain around the heme group. Top right: Cyt $c$ electrostatically attached to a $3 \mathrm{~nm}$ thioctic acid (two Au-S links per TA molecule) protected AuNP in turn covalently linked to a $\mathrm{Au}(111)$-electrode surface via a mixed cysteamíne/1-propanethiol SAM. The > 20-fold rate constant increase is indicated. Bottom: Illustration of interfacial ET via a dithiol SAM modified AuNP. One probing molecule, $\left[\mathrm{Ru}\left(\mathrm{NH}_{3}\right)_{6}\right]^{2+/ 3+}$ reacts by outer sphere ET , the other one, Ferrocene ${ }^{0 /+}$ by inner sphere ET. Adapted from Refs. 13 and 49 .
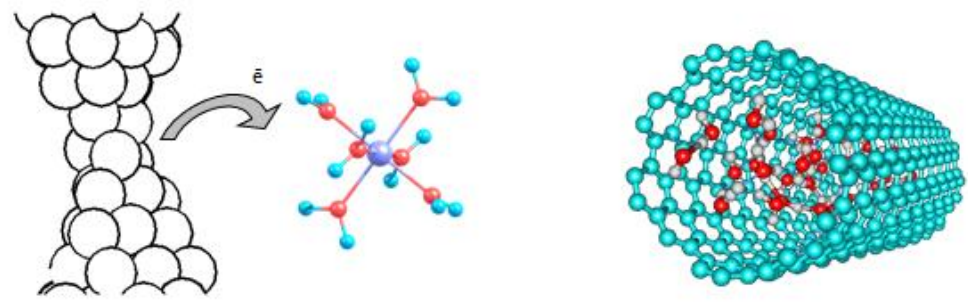

Fig. 3

Schematic views of structure and reactivity of a metal nanowire and a water-filled tube. Top: Electron transfer from a charged metal nanowire to an external molecular electron acceptor, here a hexa-aqua transition metal complex. Bottom: Water molecules inside a $(10,7)$ singlewalled carbon nanotube as derived from preliminary MD simulations at $300 \mathrm{~K}$ in progress. 